\title{
Molecular electrocatalysis at soft interfaces $\dagger$
}

\section{Manuel A. Méndez, Raheleh Partovi-Nia, $\ddagger$ Imren Hatay, Bin Su, $§$ PeiYu Ge, Astrid Olaya, Nathalie Younan, Mohamad Hojeij and Hubert H. Girault*a}

\author{
Received 17th May 2010, Accepted 13th August 2010 \\ DOI: $10.1039 / \mathrm{c0cp00590h}$
}

The fundamental aspects of electrochemistry at liquid-liquid interfaces are introduced to present the concept of molecular electrocatalysis. Here, a molecular catalyst is adsorbed at the interface to promote a proton coupled electron transfer reaction such as hydrogen evolution or oxygen reduction using lipophilic electron donors.

\section{Introduction}

An often-quoted stance in electrochemistry is: "Electrochemistry is great! The only problem is the electrode!" Indeed, for many years, the preparation of reproducible electrode surfaces has been a headache and gave bad press to electrochemical science. An easy way to alleviate this problem has been for many years to use mercury drop electrodes, which made the heyday of polarography. Another approach pioneered by the French school of Clavilier et al., ${ }^{1}$ has been to borrow techniques from surface science to prepare single crystal electrodes with wellcharacterised crystallographic faces.

For molecular electrochemists wishing to study molecular electrocatalysis, the electrode surface should be as inert as

Laboratoire d'Electrochimie Phyique et Analytique, Station 6, Ecole Polytechnique Fédérale de Lausanne, CH-1015 Lausanne,

Switzerland.E-mail: hubert.girault@epfl.ch; Fax: + 4121693 3667; Tel: +41216933145

$\dagger$ Contributed to the PCCP collection on Electrified Surface Chemistry, following the 1st Ertl Symposium on Electrochemistry and Catalysis, 11-14 April, 2010, Gwangju, South Korea.

$\ddagger$ Present address: Department of Chemistry, The University of Western Ontario, 1151 Richmond Street, London, Ontario, Canada.

$\S$ Present address: Institute of Microanalytical Systems, Department of Chemistry, Zhejiang University, 310058 Hangzhou, China.

- Hubert Girault is a member of the Ertl Center for Electrochemistry and Electrocatalysis at Gwanju Institute of technology. possible acting just as a supply or sink of electrons. In this case, the electrode can be coated with a thin film of adsorbed molecular catalysts, and a classical example has been the coating of porphyrins on electrodes to carry out oxygen reduction. However, for many reactions, the interface is an integral part of the reaction, as demonstrated by the production of oxygen on iridium oxide electrodes. ${ }^{2}$ In classical electrocatalysis, the goal is to use the intrinsic chemical properties of the interface to catalyse the reactions using the surface functional groups such as oxides to provide selectivity and efficiency.

Soft electrified interfaces such as membranes for ion-selective electrodes, biomembranes, liquid-liquid interfaces represent another class of electrochemical interfaces. Indeed, the Interface between Two Immiscible Electrolyte Solutions (ITIES) is a defect free interface where the electrochemical methodology e.g. cyclic voltammetry can be applied to study a wide range of charge transfer reactions such as ion transfer, assisted ion transfer, heterogeneous electron transfer or proton coupled electron transfer reactions. ${ }^{3}$

The purpose of this article is to present some fundamental concepts of electrochemistry at ITIES with a special focus on molecular electrocatalysis and to show how this concept can be of use for energy research. Indeed, major challenges in sustainable chemistry include the water splitting reaction,

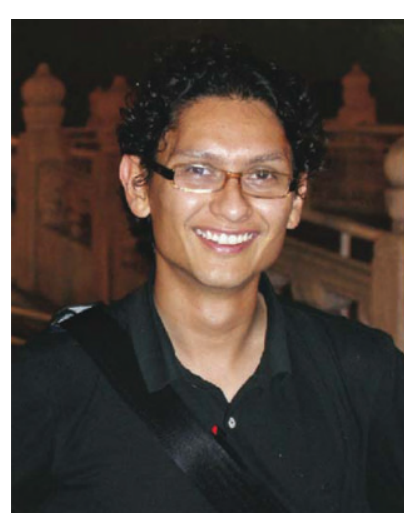

Manuel A. Méndez
Manuel A. Méndez was born in Bogota. He received his $B A$ and $M S$ in Chemistry from the National University of Colombia, Bogota, in 2005 and 2007 , respectively. In the fall of 2007, he went to work in the laboratory of Hubert H. Girault at the Ecole Polytechnique Fédérale de Lausanne (EPFL). His PhD work has involved the interaction between peptides and lipidic monolayers at liquid-liquid interfaces. At present, he is also interested in the reactivity of water-supercritical $\mathrm{CO}_{2}$ interfaces.

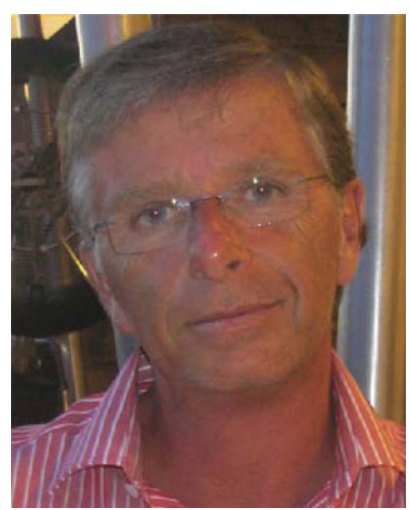

Hubert H. Girault is a Professor of Physical Chemistry at the Ecole Polytechnique Fédérale de Lausanne (EPFL), Switzerland. His research interests span from analytical to physical electrochemistry. Analytical studies include developing biosensors such as electrochemical immunosensors, new electrophoretic methods such as Offgel electrophoresis and studying the electrochemical aspects of ionisation methods for mass spectrometry. On the physical side

Hubert H. Girault

his research is mainly dedicated to investigate the electrochemical properties of liquid-liquid interfaces, and more recently to develop molecular electrocatalysis for energy research. 
oxygen reduction and carbon dioxide reduction. These reactions proceed via proton coupled electron transfer mechanisms and here ITIESs present some specificities such as the possibility to react $\mathrm{O}_{2}$ or $\mathrm{CO}_{2}$ and aqueous protons with lipophilic electron donors located in the adjacent organic phase, in the presence of adsorbed amphiphilic molecular catalysts.

\section{Voltammetry at ITIES}

\subsection{Polarised ITIES}

For more than a century, it has been known that ITIES can be polarised but it was only since the use of 4-electrode potentiostats in the eighties that the field of electrochemistry at polarised ITIES really started. In this case, two reference electrodes with Luggin capillaries are used to control the interfacial polarisation whilst two counter electrodes are used to pass the current as shown in Fig. 1.

The potential drop across the ITIES spans across two back-to-back diffuse layers and as a result the interfacial thickness is about $10-20 \mathrm{~nm}$. There have been over the last three decades many studies to determine the interfacial structure. By definition, a liquid-liquid interface is a dynamic one, with capillary waves of different amplitudes and frequencies. Capacitance measurements have shown that the two back-toback diffuse, or Gouy-Chapman layers do overlap, due to the interfacial corrugation, appearing at long time scale as a mixed solvent layer. Using a potential of mean force for the ion, Schlossman et al. have developed a generalised PoissonBoltzmann equation to analyse $\mathrm{X}$-ray reflectivity data and probe the ion distribution across the diffuse layers. ${ }^{4}$

To polarize an ITIES, it is essential to use a hydrophilic salt such as $\mathrm{LiCl}$ and a very lipophilic salt such as bis(triphenylphosphoranylidene)ammonium tetrakis(penta-fluorophenyl)borate $\left(\mathrm{BA}^{+} \mathrm{TB}^{-}\right)$. In such a system, as the interface is polarised positively (water $v s$. oil) the interfacial capacitor becomes charged (water $(+)$ organic $(-)$ ) until the polarisation is strong enough for either an aqueous cation or an organic anion to cross the interface, which can be measured as a current. Here, the Gibbs energy of transfer of $\mathrm{Li}^{+}$from water to 1,2 -dichloroethane $\left(1,2\right.$-DCE) is equal to $63 \pm 4 \mathrm{~kJ} \mathrm{~mol}^{-1}$ and that of $\mathrm{TB}^{-}$equal to $-65 \pm 4 \mathrm{~kJ} \mathrm{~mol}^{-1}$, and therefore the potential window is limited by the transfer of $\mathrm{Li}^{+}$. Inversely, when we polarise the interface negatively, we charge the

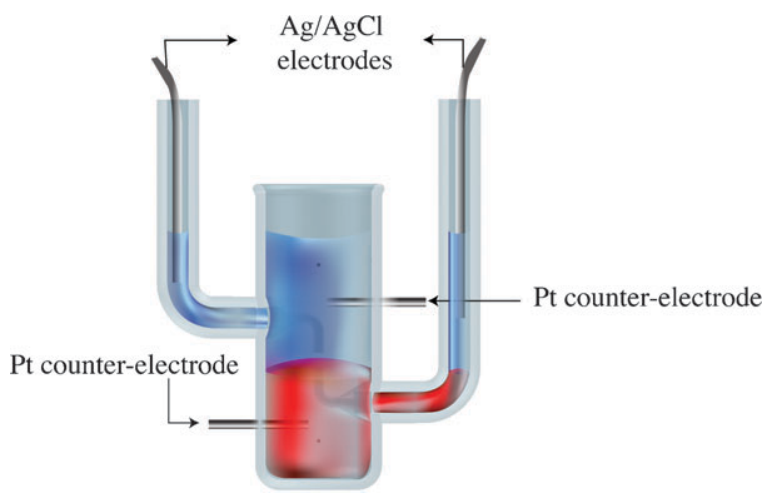

Fig. 1 Four-electrode cell for electrochemical studies of ITIES.

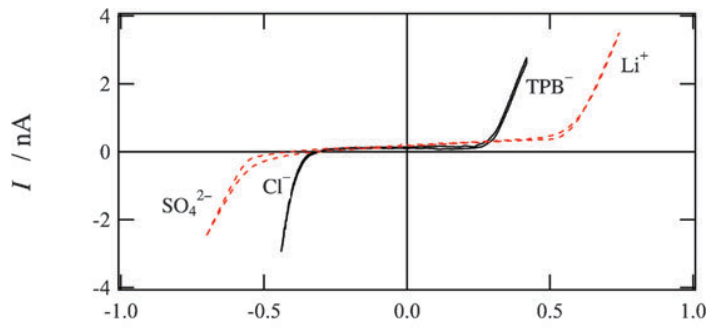

$\Delta{ }^{\mathrm{w}} \phi / \mathrm{V}$

Fig. 2 Potential window at a micro water|1,2-dichloroethane interface. Full line: $\mathrm{LiCl} / \mathrm{TDATPB}$ (tetradecylammonium tetraphenylborate) limited respectively by the transfer of $\mathrm{Cl}^{-}$and $\mathrm{TPB}^{-}$, dotted line $\mathrm{Li}_{2} \mathrm{SO}_{4} / \mathrm{BATB}$ limited respectively by the transfer of $\mathrm{SO}_{4}{ }^{2-}$ and $\mathrm{Li}^{+}$.

interfacial capacitor (water $(-) \mid$ organic $(+))$ until the polarisation is strong enough for an aqueous anion or an organic cation to cross the interface. Here, the Gibbs energy of transfer from water to 1,2-DCE of $\mathrm{Cl}^{-}$is equal to $51 \pm 4 \mathrm{~kJ} \mathrm{~mol}^{-1}$ and that of $\mathrm{BA}^{+}$equal to $-67 \pm 4 \mathrm{~kJ} \mathrm{~mol}^{-15}$ such that the potential window is limited by the transfer of chloride. When using $\mathrm{LiSO}_{4}$ instead of $\mathrm{LiCl}$, the potential window can be extended, as sulfate ions are more hydrophilic than chloride. All in all, in such a system the potential window is equal to about 1 Volt as shown in Fig. 2, where a micro-ITIES supported within a micro-hole in a thin polymer film ${ }^{6}$ has been used in order to observe the large currents limiting the potential window. It should be stressed here that the potential scale is the absolute Galvani potential difference, and that the zero of this scale corresponds to an uncharged interface equivalent to a flat band potential in semiconductor electrochemistry.

\subsection{Ion transfer reaction}

The Nernst equation for an ion transfer reaction is obtained by writing the equality of the electrochemical potentials of the ion in the two adjacent phases and is given by

$$
\Delta_{\mathrm{o}}^{\mathrm{w}} \phi=\phi^{\mathrm{w}}-\phi^{\mathrm{o}}=\Delta_{\mathrm{o}}^{\mathrm{w}} \phi_{i}^{\mathrm{o}}+\frac{R T}{z_{i} F} \ln \left(\frac{a_{i}^{\mathrm{o}}}{a_{i}^{\mathrm{w}}}\right)
$$

where $\Delta_{\circ}^{\mathrm{w}} \phi$ is the Galvani potential difference between the two phases, and $\Delta_{\mathrm{o}}^{\mathrm{w}} \phi_{i}^{\mathrm{o}}$ is the standard transfer potential of the ion $i$ expressing in a voltage scale the standard Gibbs energy of transfer $\Delta G_{\mathrm{tr}, i}^{\mathrm{o}, \mathrm{W} \rightarrow \mathrm{o}}$ from water (w) to the organic solvent (o)

$$
\Delta_{\mathrm{o}}^{\mathrm{w}} \phi_{i}^{\mathrm{o}}=\frac{\Delta G_{\mathrm{tr}, i}^{\mathrm{o}, \mathrm{w} \rightarrow \mathrm{o}}}{z_{i} F}
$$

Eqn (1) shows that when we polarise by external means, i.e. with a potentiostat, the interface positively ( $\mathrm{w} v s$. o) at potentials higher than the standard transfer potential, a cationic species $i$ will transfer to the organic phase or an anionic species $i$ will transfer to the aqueous phase.

Another way to write the Nernst equation is to define the ionic partition coefficient $P_{i}$

$$
P_{i}=\frac{a_{i}^{\mathrm{o}}}{a_{i}^{\mathrm{w}}}=\exp \left[\frac{z_{i} F}{R T}\left(\Delta_{\mathrm{o}}^{\mathrm{w}} \phi-\Delta_{\mathrm{o}}^{\mathrm{w}} \phi_{i}^{\mathrm{o}}\right)\right]=P_{i}^{\mathrm{o}} \exp \left[\frac{z_{i} F}{R T} \Delta_{\mathrm{o}}^{\mathrm{w}} \phi\right]
$$


Eqn (3) shows that the partition of ions depends on the Galvani potential whereas that of neutral species depends only on the nature of the solvents.

Another way to polarise an ITIES is to choose supporting electrolytes such that the distribution of ions in excess will fix the interfacial polarisation. Let us consider a simple example. When two immiscible solvents contains the same electrolyte $\mathrm{C}^{+} \mathrm{A}^{-}$, the partition of the electrolyte will result in a polarisation of the interface, and the Galvani potential there established is called the distribution potential given by

$$
\Delta_{\mathrm{o}}^{\mathrm{w}} \phi=\frac{\Delta_{\mathrm{o}}^{\mathrm{w}} \phi_{\mathrm{C}^{+}}^{\mathrm{o}}+\Delta_{\mathrm{o}}^{\mathrm{w}} \phi_{\mathrm{A}^{-}}^{\mathrm{o}}}{2}+\frac{R T}{2 F} \ln \left(\frac{\gamma_{\mathrm{C}^{+}}^{\mathrm{o}} \gamma_{\mathrm{A}^{-}}^{\mathrm{w}}}{\gamma_{\mathrm{C}^{+}}^{\mathrm{w}} \gamma_{\mathrm{A}^{-}}^{o}}\right)
$$

where $\gamma$ represents the ionic activity coefficients. When many ionic species are present in the adjacent immiscible solutions, the Galvani potential difference can be calculated numerically if the standard transfer potentials of the different species are known.

\subsection{Assisted ion transfer reaction}

Ion transfer reactions can be facilitated by different complexation reactions occurring in either phase as shown in Fig. 3.

The scheme illustrated in Fig. 3 applies also to acid-base reactions. In this case, it is convenient to use ionic distribution diagrams (also called ionic partition diagrams), which like a Pourbaix diagram show zones of predominance in a plot of the Galvani potential difference as a function of the $\mathrm{pH}^{7,8}$

\subsection{Electron transfer reaction}

Polarised liquid-liquid interfaces can be the locus of heterogeneous electron transfer reaction between say an oxidised species in water and a reduced species in the organic phase as shown in Fig. 4.

A widely studied reaction has been the electron transfer reaction between aqueous ferri-ferrocyanide and organic ferroceniumferrocene, as recently discussed., ${ }^{9,10}$

The major characteristic of this type of electron transfer reactions is to be potential dependent, i.e. it is possible to drive

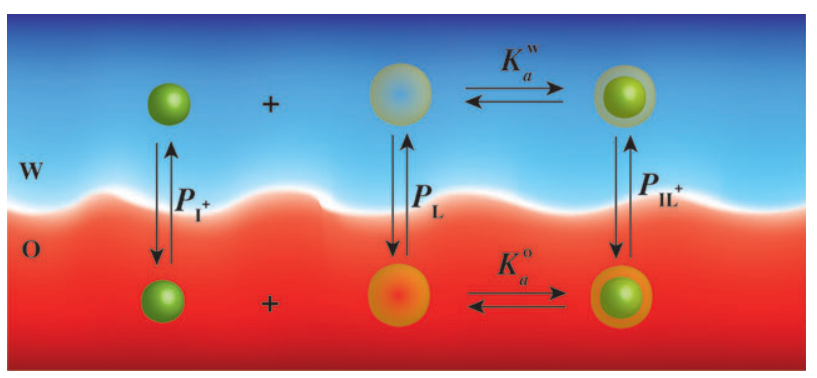

Fig. 3 Thermodynamic constants for assisted ion transfer reactions.

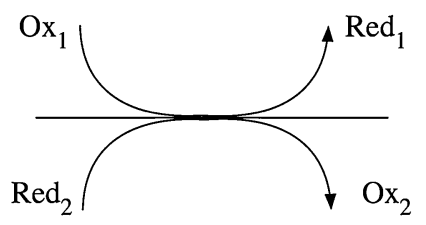

Fig. 4 Heterogeneous redox reaction at a liquid|liquid interface. the reaction in either direction by controlling the interfacial applied potential difference.

$$
\mathrm{O}_{1}^{\mathrm{w}}+\mathrm{R}_{2}^{\mathrm{o}} \leftrightharpoons \mathrm{R}_{1}^{\mathrm{W}}+\mathrm{O}_{2}^{\mathrm{O}}
$$

At equilibrium, we can write the following equality of the electrochemical potentials

$$
\tilde{\mu}_{\mathrm{R}_{1}}^{\mathrm{W}}+\tilde{\mu}_{\mathrm{O}_{2}}^{\mathrm{o}}=\tilde{\mu}_{\mathrm{O}_{1}}^{\mathrm{W}}+\tilde{\mu}_{\mathrm{R}_{2}}^{\mathrm{o}}
$$

and, developing this expression for a single electron transfer reaction, we obtain a Nernst equation for this heterogeneous electron transfer, i.e.

$$
\Delta_{\mathrm{o}}^{\mathrm{w}} \phi=\Delta_{\mathrm{o}}^{\mathrm{w}} \phi_{\mathrm{ET}}^{\mathrm{o}}+\frac{R T}{F} \ln \left(\frac{a_{\mathrm{R}_{1}}^{\mathrm{w}} a_{\mathrm{O}_{2}}^{\mathrm{o}}}{a_{\mathrm{O}_{1}}^{\mathrm{w}} a_{\mathrm{R}_{2}}^{\mathrm{o}}}\right)
$$

with $\Delta_{\mathrm{O}}^{\mathrm{w}} \phi_{\mathrm{ET}}^{\mathrm{o}}$ the standard redox potential for the interfacial transfer of electrons. This value is simply the difference of the standard redox potential for the two redox couples, both expressed with respect to the aqueous Standard Hydrogen Electrode (SHE).

$$
\Delta_{\mathrm{O}}^{\mathrm{w}} \phi_{\mathrm{ET}}^{\mathrm{o}}=\left[E_{\mathrm{O}_{2} / \mathrm{R}_{2}}^{\mathrm{o}}\right]_{\mathrm{SHE}}^{\mathrm{o}}-\left[E_{\mathrm{O}_{1} / \mathrm{R}_{1}}^{\mathrm{o}}\right]_{\mathrm{SHE}}^{\mathrm{w}}
$$

Of course, it is experimentally difficult to determine that standard redox potential of organic redox couples with respect to the aqueous SHE, and one way to circumvent this difficulty is to measure the organic standard redox potential on the ferrocene scale that can be referred to the aqueous SHE by different thermodynamic cycles. In the case of 1,2-dichloroethane, it has been found that:

$$
\left[E_{\mathrm{Fc}^{+} / \mathrm{Fc}}^{\mathrm{o}}\right]_{\mathrm{SHE}}^{\mathrm{DCE}}=0.64 \pm 0.05 \mathrm{~V}
$$

When the standard redox potential in water is known, for example for the reduction of oxygen to hydrogen peroxide, it is then possible to calculate its value in 1,2-DCE with respect to the aqueous SHE if the different Gibbs energies of transfer are known.

$$
\left[E_{\mathrm{O}_{2} / \mathrm{H}_{2} \mathrm{O}_{2}}^{\mathrm{o}}\right]_{\mathrm{SHE}}^{\mathrm{o}}=\left[E_{\mathrm{O}_{2} / \mathrm{H}_{2} \mathrm{O}_{2}}^{\mathrm{o}}\right]_{\mathrm{SHE}}^{\mathrm{w}}-\left(\Delta G_{\mathrm{tr}, \mathrm{H}_{2} \mathrm{O}_{2}}^{\mathrm{o}, \mathrm{w} \rightarrow \mathrm{o}}-2 \Delta G_{\mathrm{tr}, \mathrm{H}^{+}}^{\mathrm{o}, \mathrm{w} \rightarrow \mathrm{o}}\right) / 2 F
$$

Fig. 5 illustrates the redox scales at the water|1,2-DCE interface for the reduction of oxygen. ${ }^{11}$

It is interesting to see that the reduction of molecular oxygen to peroxide anion occurs at a more negative potential in the organic solvent, as it involves the formation of an ionic species. Inversely, the reduction of molecular oxygen to water occurs at a higher potential as it involves the disappearance of four protons. Electron transfer reactions at ITIES can be studied by cyclic voltammetry, but care has be taken when analysing the voltammetric response that depends strongly on the concentration ratio of the reactants. ${ }^{12} \mathrm{~A}$ key issue when studying heterogeneous electron transfer reactions is to ensure that the reactants and the products do not partition to the adjacent phase. ${ }^{9}$ Indeed, in the case of ferrocene, its partition to water cannot always be neglected and it has been shown that the reaction can take place on the aqueous side of interface. $^{10}$ 


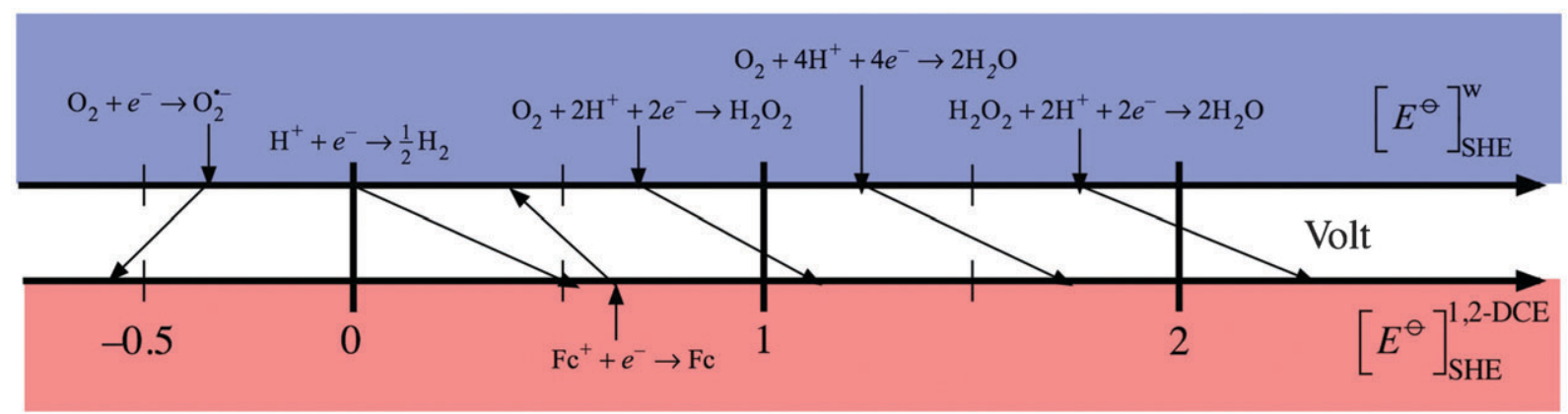

Fig. 5 Redox potential scale for oxygen in water (top scale) and in 1,2-dichloroethane (bottom scale) versus the Standard Hydrogen Electrode (SHE).

\subsection{Proton coupled electron transfer reactions}

Polarised liquid-liquid systems can be used to react organometallic complexes usually sparingly soluble in water with aqueous protons. Fig. 6 illustrates two examples such as the reduction of protons by metallocenes and the reduction of oxygen catalysed by amphiphilic molecular catalysts. A catalyst recently studied is cobalt porphine depicted in Fig. 7a, a planar molecule that was found to adsorb at the water|1,2-dichloroethane interface. ${ }^{13}$ In this case, a voltammetric signal could be observed at positive potentials when all the four reactants were present, namely oxygen, aqueous protons, adsorbed cobalt porphines acting as a catalyst, and ferrocene as electron donor in the organic phase.

Fig. 7 shows such a Proton Coupled Electron Transfer (PCET) wave for a similar system to that of ref. 13, but with dimethylferrocene as electron donor. The signal at positive potentials corresponds to the PCET reaction, but
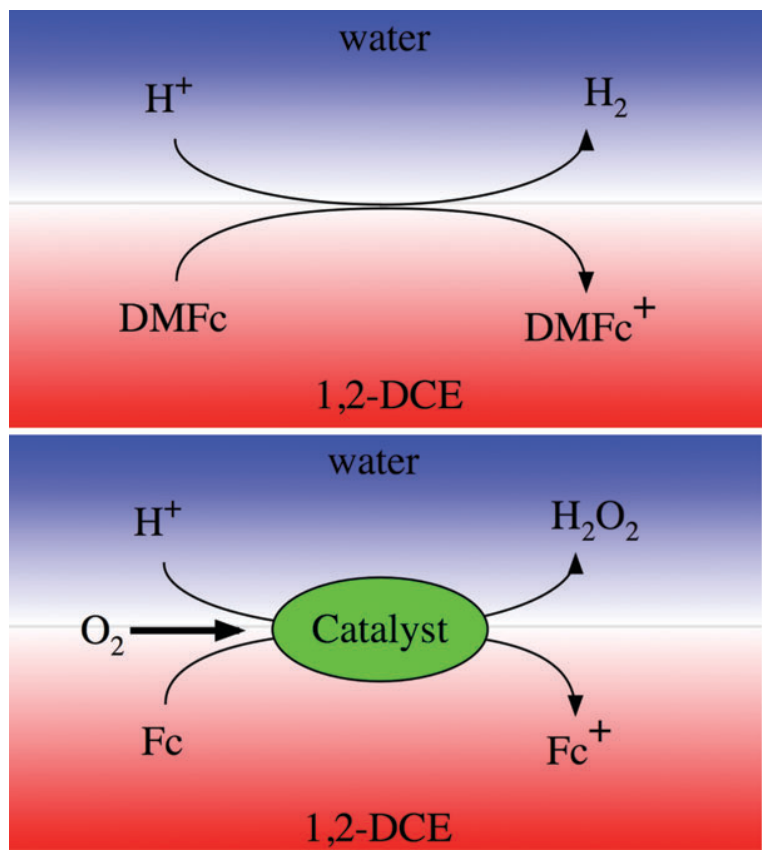

Fig. 6 Hydrogen evolution at ITIES using an organic electron donor, here decamethylferrocene (DMFc) (top) and oxygen reduction at ITIES using an adsorbed molecular catalyst such as a porphyrin and a simple electron donor such as ferrocene (bottom).

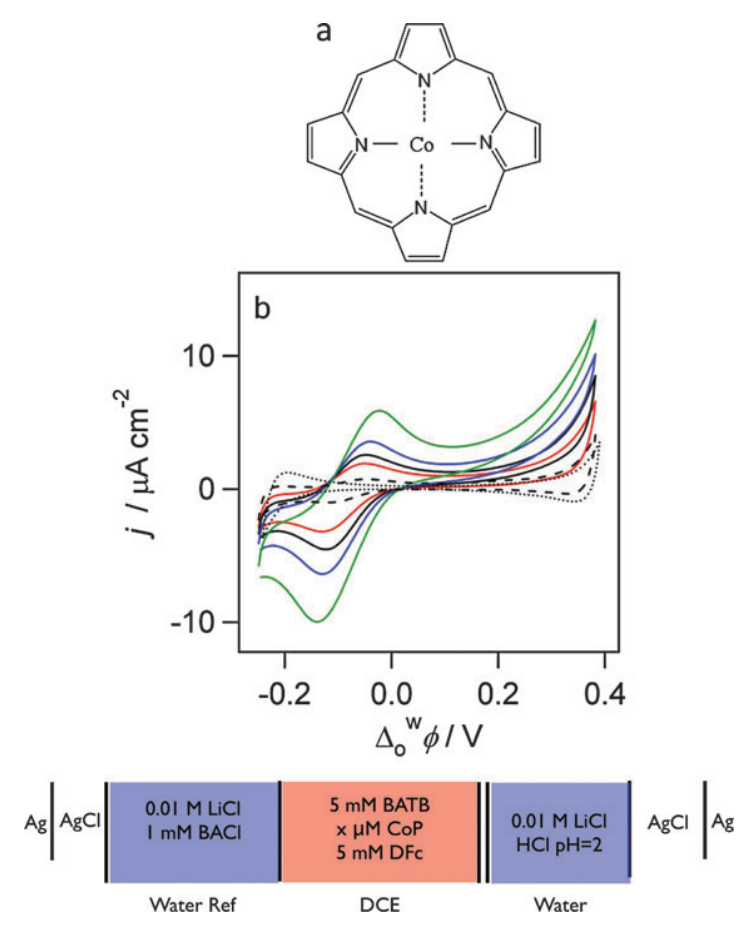

Fig. 7 (a) Cobalt porphine CoP, (b) cyclic voltammograms in the presence of dimethylferrocene ( $\mathrm{DFc}$ ) at various concentrations of $\mathrm{CoP}$ in 1,2-DCE, $10 \mu \mathrm{M}$ (red), $25 \mu \mathrm{M}$ (full black), $50 \mu \mathrm{M}$ (blue) and $75 \mu \mathrm{M}$ (green). Dotted line, supporting electrolyte BATB only, dashed line in the presence of $\mathrm{DFc}$ but in the absence of CoP. Scan rate: $50 \mathrm{mV} \mathrm{s}^{-1}$.

unfortunately no model has been developed yet to analyse quantitatively these voltammetry data. From a qualitative viewpoint, one can notice the lack of reverse current wave on the reverse scan. The signal observed between -0.2 and 0 Volt corresponds to a simple ion transfer reaction, namely that of dimethylferrocenium from 1,2-DCE to water when scanning in the negative direction, and back to 1,2-DCE when scanning back in the positive direction. Voltammetry at ITIES is a valuable tool to study proton coupled electron transfer reactions of biological interest. This has been pioneered by the group of S. Kihara who has investigated the oxidation of $\beta$-nicotinamide adenine dinucleotide (NADH) by quinone derivatives, ${ }^{14}$ the respiration mimetic reaction process of flavin mononucleotide oxidation by a ferrocene derivative, ${ }^{15}$ or the interfacial oxidation of vitamin $\mathrm{E}$ by aqueous permanganate. ${ }^{16}$ 


\section{Hydrogen evolution by PCET}

It has been known for many years that metallocenes and ferrocenophanes ${ }^{17,18}$ can react with organic acids to form hydrogen. In particular, Koelle et al. have studied by pulse radiolysis the kinetics of proton reduction by cobaltocene. ${ }^{19}$ More recently, we have shown that under anaerobic conditions decamethylferrocene (DMFc) in 1,2-dichloroethane could be oxidised by aqueous protons in biphasic reactions with the production of molecular hydrogen. ${ }^{20}$

Globally, the reaction can be written

$$
2 \mathrm{DMFc}^{\mathrm{DCE}}+2 \mathrm{H}^{+\mathrm{w}} \leftrightharpoons 2 \mathrm{DMFc}^{+\mathrm{DCE}}+\mathrm{H}_{2}
$$

The standard Gibbs energy can be calculated considering the respective standard redox potentials and is given by

$$
\Delta G^{\mathrm{o}}=F\left(\left[E_{\mathrm{DMFc}^{+} / \mathrm{DMFc}}^{\mathrm{o}}\right]_{\mathrm{SHE}}^{\mathrm{DCE}}-\left[E_{\mathrm{H}^{+} / \frac{1}{2} \mathrm{H}_{2}}^{\mathrm{o}}\right]_{\mathrm{SHE}}^{\mathrm{w}}\right)=4 \mathrm{~kJ} \mathrm{~mol}^{-1}
$$

As can be seen the reaction is slightly endergonic, and therefore for the reaction to proceed it is required to polarise the interface positively as shown in Fig. 8. Indeed, the Nernst equation for this system reads

$$
\Delta_{\mathrm{o}}^{\mathrm{w}} \phi=\left[E_{\mathrm{DMFc}^{+} / \mathrm{DMFc}}^{\mathrm{o}}\right]_{\mathrm{SHE}}^{\mathrm{DCE}}+\frac{R T}{F} \ln \left(\frac{a_{\mathrm{DMFc}^{+}}^{\mathrm{DCE}}}{a_{\mathrm{DMFc}}^{\mathrm{DCE}}}\right)+\frac{R T}{F} \ln 10 \mathrm{pH}
$$

The reaction was studied by voltammetry and shown to be potential dependent as it only occurs at positive potentials where the initial step is a proton transfer reaction facilitated by DMFc. The pH dependence illustrated in Fig. 8 in anaerobic conditions clearly shows that the current wave at positive potentials shifts with $\mathrm{pH}$.

This can result either from a direct heterogeneous electron transfer reaction as shown by the Nernst equation (10) or from a multi-step reaction involving the protonation of DMFc acting here as a base. The basicity of ferrocene derivatives has been studied both experimentally ${ }^{21}$ and theoretically ${ }^{22}$ since the early work of Richards et al. ${ }^{23}$ Considering that

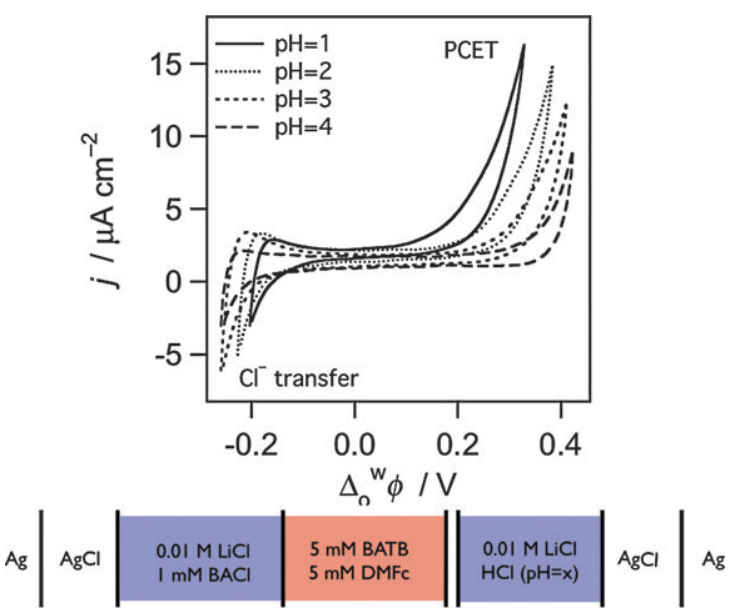

Fig. 8 Cyclic voltammograms at different $\mathrm{pH}$ values showing that the PCET current shifts $60 \mathrm{mV}$ per $\mathrm{pH}$. Scan rate in all cases: $50 \mathrm{mV} \mathrm{s}{ }^{-1}$.

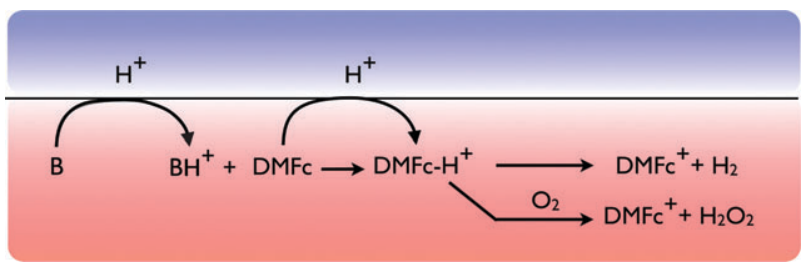

Fig. 9 Reduction of protons and oxygen at polarised ITIES.

hydrogen can be produced in bulk 1,2-DCE using the organic acid HTB according to the reaction ${ }^{24}$

$\mathrm{DMFc}^{\mathrm{DCE}}+\mathrm{H}^{+} \mathrm{TB}^{-\mathrm{DCE}} \rightleftharpoons \mathrm{DMFc}^{+\mathrm{DCE}}+\mathrm{TB}^{-\mathrm{DCE}}+\frac{1}{2} \mathrm{H}_{2}$

having a standard Gibbs energy value of $-51 \mathrm{~kJ} \mathrm{~mol}^{-1}$ it is likely that the biphasic reaction at the polarised interface proceeds by the interfacial protonation of DMFc as shown in Fig. 9.

The other following steps are still a matter for discussion. The reaction may proceed via a bimolecular route between two protonated [DMFc-H] ${ }^{+}$to produce two $\mathrm{DMFc}^{+}$and $\mathrm{H}_{2}$. Alternatively, the reaction may proceed by a proton attack on a hydride form of the protonated complex $\left[\mathrm{DMFc}^{\mathrm{IV}}-\mathrm{H}\right]^{+}$to yield $\left[\mathrm{DMFc}^{\mathrm{IV}}\right]^{2+}$ plus $\mathrm{H}_{2}$ followed by a reduction of $\left[\mathrm{DMFc}^{\mathrm{IV}}\right]^{2+}$ by DMFc. The final possibility is a reduction route involving the reduction of $[\mathrm{DMFc}-\mathrm{H}]^{+}$to form $[\mathrm{DMFc}-\mathrm{H}]$ followed by a proton attack. These reactions can be compared to the hydrogen evolution reaction on solid electrodes known as the Volmer-Tafel-Heyrovsky reaction as indicated in Table 1.

The initial DMFc protonation has also been studied by surface tension measurements of electrocapillary curves. We have shown that $[\mathrm{DMFc}-\mathrm{H}]^{+}$does adsorb at the interface prior to the proton transfer reaction, meaning that the protonation reaction itself occurs in two steps; first an interfacial protonation of $\mathrm{DMFc}$ resulting to adsorbed $[\mathrm{DMFc}-\mathrm{H}]^{+}$, and then desorption of $[\mathrm{DMFc}-\mathrm{H}]^{+}$towards the organic phase.

The protonation of DMFc can be facilitated by the use of organic bases such as dodecylaniline ${ }^{11}$ as illustrated in Fig. 9, suggesting that the rate-limiting step is the formation of $[\mathrm{DMFc}-\mathrm{H}]^{+}$.

In the case of shake flask reactions, where we contact an aqueous solution of sulfuric acid with a solution of DMFc in 1,2-DCE, the reaction only proceeds if the salt LiTB is added to the aqueous phase. The presence of the lipophilic anion in the aqueous phase results in a proton pumping reaction

Table 1 Hydrogen evolution mechanism on a metallic electrode or at an ITIES using decamethylferrocene

\begin{tabular}{ll}
\hline Electrode reaction & Bulk reaction \\
\hline Volmer reaction & Protonation \\
$\mathrm{M}+\mathrm{H}^{+} \rightarrow \mathrm{M}-\mathrm{H}_{\text {ads }}+\mathrm{e}^{-}$ & $\mathrm{Fe}^{\mathrm{II}}+\mathrm{H}^{+} \rightarrow[\mathrm{Fe}-\mathrm{H}]^{+}$ \\
Tafel reaction & Bimolecular reaction \\
$2 \mathrm{M}-\mathrm{H}_{\text {ads }} \rightarrow 2 \mathrm{M}+\mathrm{H}_{2}$ & $2[\mathrm{Fe}-\mathrm{H}]^{+} \rightarrow 2[\mathrm{Fe}]^{\mathrm{III}}+\mathrm{H}_{2}$ \\
Heyrovsky reaction & Proton attack pathway \\
$\mathrm{M}-\mathrm{H}_{\text {ads }}+\mathrm{H}^{+} \rightarrow \mathrm{M}+\mathrm{e}^{-}+\mathrm{H}_{2}[\mathrm{Fe}-\mathrm{H}]^{+}+\mathrm{Fe}^{\mathrm{II}} \rightarrow[\mathrm{Fe}-\mathrm{H}]+\left[\mathrm{Fe} e^{\mathrm{III}}\right]^{+}$ \\
- & {$[\mathrm{Fe}-\mathrm{H}]+\mathrm{H}^{+} \rightarrow\left[\mathrm{Fe}^{\mathrm{III}}\right]^{+}+\mathrm{H}_{2}$} \\
- & Reduction pathway \\
- & {$[\mathrm{Fe}-\mathrm{H}]^{+}+\mathrm{H}^{+} \rightarrow\left[\mathrm{Fe}^{\mathrm{IV}}\right]^{2+}+\mathrm{H}_{2}$} \\
- & {$\left[\mathrm{Fe}^{\mathrm{IV}}\right]^{2+}+\mathrm{Fe}^{\mathrm{II}} \rightarrow 2\left[\mathrm{Fe}^{\mathrm{III}}\right]^{+}$} \\
\hline
\end{tabular}


associated to the extraction of the acid HTB to the organic phase. In this case, the reaction can be written

$$
\mathrm{DMFc}^{\mathrm{DCE}}+\mathrm{H}^{+} \mathrm{TB}^{-\mathrm{w}} \rightleftharpoons \mathrm{DMFc}^{+\mathrm{DCE}}+\mathrm{TB}^{-\mathrm{DCE}}+\frac{1}{2} \mathrm{H}_{2}
$$

This reaction is exergonic, $\Delta G^{\circ}=-61 \mathrm{~kJ} \mathrm{~mol}^{-1}$, the main driving force being the proton pump associated to the lipophilicity of the anions $\mathrm{TB}^{-}$dragging protons to the organic phase.

\section{Oxygen reduction by PCET}

Since the early work of Cunnane et $a l^{25}$ that showed by voltammetry that oxygen could be reduced at a liquid-liquid interface by decamethylferrocene (DMFc), oxygen reduction has also been studied using flavin mononucleotide (FMN) as a catalyst. ${ }^{15}$ Indeed, it has been proposed that DMFc in 1,2DCE could reduce aqueous FMN to the semiquinone form $\left(\mathrm{FMNH}^{\bullet}\right)$ that was re-oxidised by dissolved oxygen. Oxygen reduction has also been shown to occur when using tetrachlorohydroquinone $\left(\mathrm{QH}_{2} \mathrm{Cl}_{4}\right)$ as the electron donor yielding either $\mathrm{H}_{2} \mathrm{O}$ or $\mathrm{H}_{2} \mathrm{O}_{2}$ depending on the applied potential difference. $^{26}$ Liljeroth et al. have also shown that electrogenerated $\mathrm{C}_{60}{ }^{-}$could reduce $\mathrm{O}_{2}{ }^{27}$

More recently, Su et al. have revisited oxygen reduction by $\mathrm{DMFc}^{28}$ and have shown that the reaction proceeds first by the protonation of decamethylferrocene on the metal center. The protonation of DMFc occurs only in the presence of a supporting electrolyte including a weakly coordinating ion such as tetrakis(pentafluorophenyl)borate $\left(\mathrm{TB}^{-}\right)$.

Also, it has been shown that the presence of organic bases such as dodecylaniline could be used to facilitate the proton extraction from the aqueous to the organic phase. ${ }^{11}$ Globally, the reaction can be written

$$
2 \mathrm{DMFc}^{\mathrm{DCE}}+2 \mathrm{H}^{+\mathrm{w}}+\mathrm{O}_{2} \rightleftharpoons 2 \mathrm{DMFc}^{+\mathrm{DCE}}+\mathrm{H}_{2} \mathrm{O}_{2}^{\mathrm{w}}
$$

The standard Gibbs energy can be also calculated considering the respective standard redox potentials and the reaction is found to be exergonic

$\Delta G^{\mathrm{o}}=F\left(2\left[E_{\mathrm{DMFc}}^{\mathrm{o}} / \mathrm{DMFc}_{\mathrm{SHE}}-\left[E_{\mathrm{O}_{2} / \mathrm{H}_{2} \mathrm{O}_{2}}^{\mathrm{DCE}}\right]_{\mathrm{SHE}}^{\mathrm{w}}\right)=-60 \mathrm{~kJ} \mathrm{~mol}^{-1}\right.$

The potential dependence of the production of $\mathrm{H}_{2} \mathrm{O}_{2}$ at polarised ITIES was studied by Scanning Electrochemical Microscopy (SECM), and it was shown using a platinum microelectrode located in water but closed to the liquid-liquid interface that the detection of $\mathrm{H}_{2} \mathrm{O}_{2}$ was concomitant to the voltammetric signal at the ITIES for the proton transfer reaction facilitated by $\mathrm{DMFc}^{29}$ similar to that shown in Fig. 8 for anaerobic conditions. The fact that the voltammetry does not depend on the presence of oxygen shows that the first step of oxygen reduction is the protonation of DMFc. DFT calculations have shown that the next step is the binding of $\mathrm{O}_{2}$ to $[\mathrm{DMFc}-\mathrm{H}]^{+}$, followed by the release of the hydroperoxyl radical and the formation of $\mathrm{DMFc}^{+}{ }^{24}$

The reactivity of DMFc at a polarised ITIES can be summarized in Fig. 9, and in fact we have shown that the proton reduction competes with oxygen reduction in aerobic conditions. ${ }^{24}$ Of course, the redox potential for the reduction of $\mathrm{O}_{2}$ being much more positive than for the reduction of the aqueous protons, this is not surprising that with a larger driving force the reduction of $\mathrm{O}_{2}$ occurs quasi-instantly by contacting the biphasic system whilst the evolution of $\mathrm{H}_{2}$ is a much slower process.

\section{Molecular electrocatalysis}

Molecular electrocatalysis usually consists in modifying an electrode surface by a molecular catalyst. Amongst the many systems studied, one can cite porphyrin modified electrodes pioneered by Collman et al. ${ }^{30}$ for 4-electron oxygen reduction and for photovoltaic applications as recently reviewed. ${ }^{31}$ To circumvent these inherent difficulties, Shi and Anson pioneered the concept of a supported ITIES where the working electrode is covered by a thin layer of organic solvents. ${ }^{32}$ This methodology was first used to measure the rate of heterogeneous electron transfer reactions at ITIES $^{33,34}$ using a nitrobenzene film including reactants such as ferrocene $(\mathrm{Fc})$, decamethylferrocene (DMFc), zinc tetraphenylporphyrin $\left(\mathrm{ZnTPP}^{+}\right)$and cobalt tetraphenylporphyrin $(\mathrm{CoTPP})^{2+}$ in contact with aqueous solutions containing $\mathrm{Fe}(\mathrm{CN})_{6}^{3-/ 4-}$, $\mathrm{Ru}(\mathrm{CN})_{6}{ }^{4-}, \mathrm{Mo}(\mathrm{CN})_{8}{ }^{4-}$, and $\mathrm{IrCl}_{6}{ }^{2-}$. Then, this approach has been used to study proton coupled electron transfer reactions where the reduction of tetrachloroquinone was shown to drive proton transfer reactions across the ITIES as shown in Fig. 10, ${ }^{35}$ and the authors concluded "Choosing conditions that lead to rapid proton transfer into nitrobenzene (and related solvents) may be important in catalytic applications such as the electroreduction of $\mathrm{O}_{2}$ in acidified nonaqueous solvents using homogeneous catalysts (for example, metalloporphyrins) that are insoluble in purely aqueous media".

In a subsequent publication, ${ }^{36}$ Anson et al. reported the reduction of molecular oxygen at graphite electrodes covered by a thin layer of benzonitrile about 30 microns thick and doped with cobalt 5,10,15,20-tetraphenylporphyrin (CoTPP) as illustrated in Fig. 11. It was shown that the catalytic efficiency of CoTPP is greater when it is dissolved in thin layers of acidified benzonitrile than when it is directly adsorbed on the graphite electrodes. It was also shown that the 4-electron pathways represented a significant contribution to the current response.

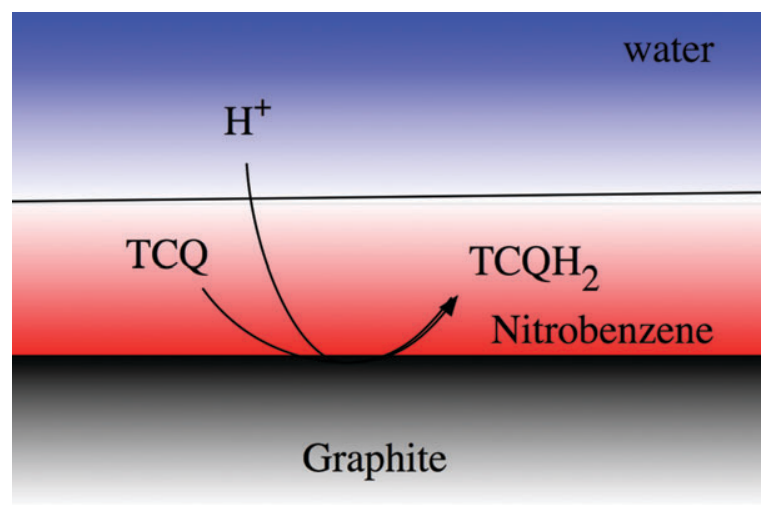

Fig. 10 Reduction of tetrachloroquinone (TCQ) in a nitrobenzene film supported on a graphite electrode acting as a proton pump. ${ }^{35}$ 
We have recently studied oxygen reduction at the polarised water/1,2-dichloroethane interface catalysed by different cobalt porphyrins compounds such as CoTPP, ${ }^{37}$ cobalt(II) 2,3,7,8,12,13,17,18-octaethylporphyrin (CoOEP), ${ }^{38}$ cobalt(II) porphine (CoP) ${ }^{13}$ amphiphilic cobalt(II) 2,8,13,17-tetraethyl3,7,12,18-tetramethyl-5-p-amino-phenylporphyrin $\quad(\mathrm{CoAP})^{39}$ using ferrocene as a sacrificial electron donor that does not react with molecular oxygen on the time scale of hours. The reduction mechanism common to all these cobalt porphyrin molecules is shown in Fig. 12, the major difference stemming from their degree of adsorption at the interface or from their redox oxidation potential.

For all these porphyrins, it is believed that the protonation of the cobalt porphyrin oxygen complex takes place at the interface. In most cases, the cobalt porphyrin oxygen complexes do adsorb at the interface prior to the protonation. Of course, the interfacial adsorption of amphiphilic porphyrins, such as CoAP, and porphyrins that stack easily, such as $\mathrm{CoP}$, is much stronger with the possible formation of stacked molecules, as in the case of CoP.

In the case of CoTPP rather large concentrations of porphyrins $(\sim \mathrm{mM}$ range) are required to observe the voltammetric signature of the protonation step as shown in Fig. 13.

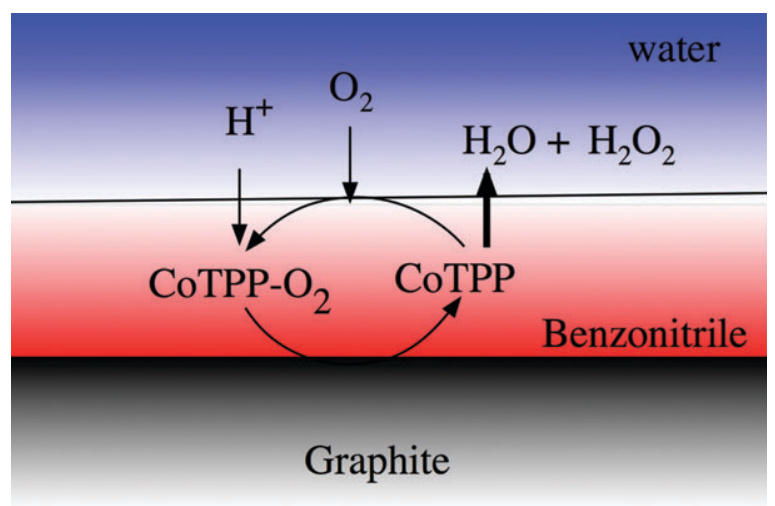

Fig. 11 Oxygen reduction on a benzonitrile film supported on a graphite electrode. $^{36}$

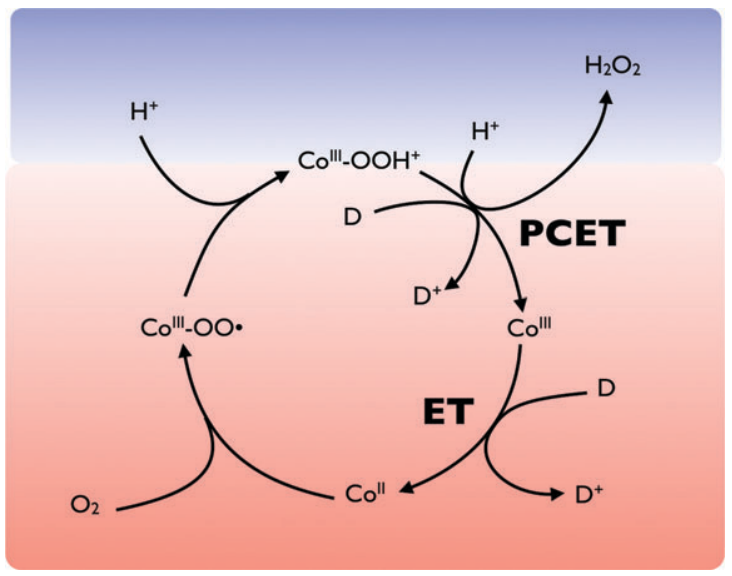

Fig. 12 Oxygen reduction catalyzed by cobalt porphyrins in biphasic systems.
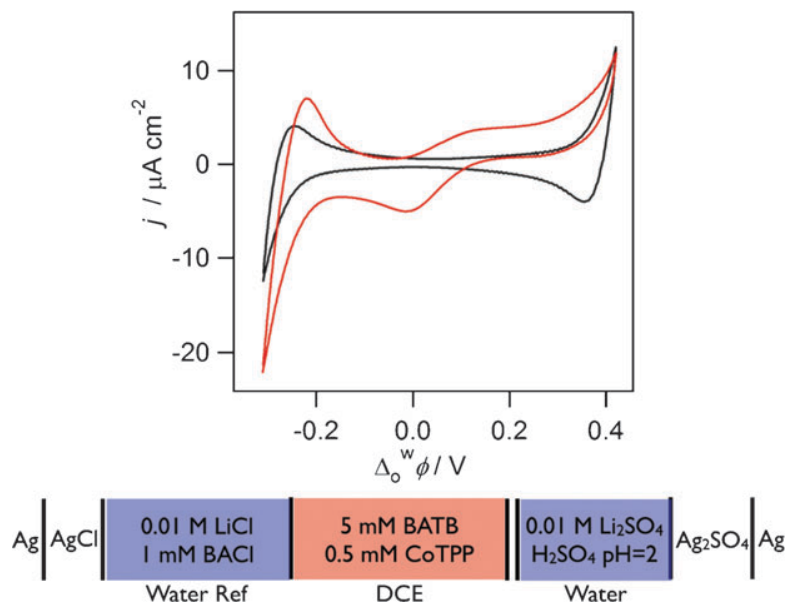

Fig. 13 Cyclic voltammograms for the cell shown and the corresponding potential window. The current wave in the middle of the potential window is proportional to the CoTPP concentration.

Furthermore in the case of CoOEP, the redox potential is low:

$$
\left[E_{\mathrm{CoOEP}}^{\mathrm{o}} / \mathrm{CoOEP}\right]_{\mathrm{SHE}}^{\mathrm{DCE}}=0.69 \mathrm{~V}
$$

and no sacrificial electron donors are required as CoOEP is oxidised during the course of the reaction.

The protonation of free base porphyrins can also be studied using voltammetry at ITIES. In the case of $\mathrm{H}_{2}$ TPP, it was even possible to resolve the two successive protonations ${ }^{40}$ and the $\mathrm{p} K_{\mathrm{a}}$ values found to be equal to 9.8 and 6.0 respectively when using $\mathrm{TB}^{-}$as the organic anion. Similar values of 10.4 and 6.7 were found ${ }^{41}$ when using tetrakis(4-chloro-phenyl)borate highlighting the influence of the counter ions in the measurement of the acidity constants. In this study, it was shown that the rather slow reduction of oxygen by decamethylferrocene $(\mathrm{DMFc})$ at the polarized water|1,2-dichloroethane interface proceeds remarkably faster in the presence of tetraphenylporphyrin monoacid $\left(\mathrm{H}_{3} \mathrm{TPP}^{+}\right)$and diacid $\left(\mathrm{H}_{4} \mathrm{TPP}^{2+}\right)$ suggesting that these protonated porphyrins can activate molecular oxygen.

\section{Perspectives and conclusions}

Liquid-liquid interfaces provide a defect free interface to study proton coupled electron transfer reactions where aqueous protons can react with organic electron donors in the presence of adsorbed catalysts. These interfaces can be polarised by an external circuit or by a judicious choice of supporting electrolyte to provide an electrochemical control of the reaction driving force. In the same way that biological membranes can be viewed as a means to separate reactants and products of successive charge transfer reactions so as to avoid the back transfer reactions; the reactants and the products can be separated at liquid-liquid interfaces according to their hydrophobicity thereby vectorising the electron transfer processes.

In biological systems, the catalyst organisation is made mainly by self-assembly. One goal of molecular electrocatalysis is also to self-assemble systems. For example, we have shown that anionic zinc meso-tetrakis( $p$-sulfonatophenyl)-porphyrin 

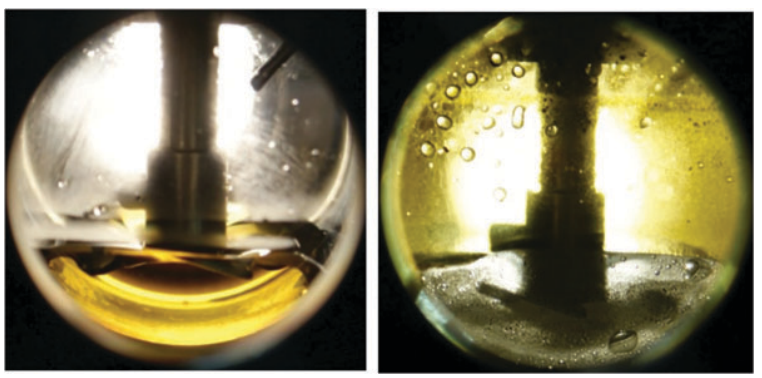

Fig. 14 Left: bromophenol blue in water (bottom) in contact with supercritical $\mathrm{CO}_{2}$. Right: decamethylferrocene in supercritical $\mathrm{CO}_{2}$ (top) in contact with water. In both cases: $T=40{ }^{\circ} \mathrm{C}$ and $P=8 \mathrm{MPa}$.

and cationic zinc tetrakis $(N$-methylpyridyl)porphyrin dimers can be used as photocatalysts. ${ }^{42-44}$ In the case of oxygen reduction, it could be interesting to self assemble porphyrin dimers to drive the 4-electron reduction of oxygen thereby avoiding the lengthy synthesis of cofacial porphyrin dyads. Indeed, Anson et al. had shown that CoP could drive such a 4-electron reduction on solid electrodes, ${ }^{45}$ and it should be very interesting to see if similar reactions could be observed at ITIES.

Another aspect of biocatalysis is the self-repairing aspect. In the case of the photosystem II for oxygen evolution from water, photo-oxidative degradation by singlet oxygen can be observed as recently reviewed, ${ }^{46}$ and therefore new photosystems must be produced. On solid electrodes, the photodegradation of the molecular catalysts is often a problem, but at ITIES the degradation of the amphiphilic catalysts would result in desorption from the interface and the adsorption of other catalysts from the adjacent bulk.

In a perspective article, the main question is: what's next?

One way the field can develop is to study molecular catalysis at non conventional interfaces using for example ionic liquids as pioneered by the group of Kakiuchi, ${ }^{47}$ or using very nonpolar solvents as pioneered by Volkov et al. ${ }^{48}$

Another interesting system is the water-supercritical $\mathrm{CO}_{2}$ interface. Indeed, very mechanically defined interfaces can be obtained as illustrated in Fig. 14, and photo-electrochemistry of such interfaces is worthy of investigation.

Fig. 14 shows a biphasic water-supercritical $\mathrm{CO}_{2}$ system illustrating that the $\mathrm{pH}$ of the aqueous phase becomes acidic under such conditions and showing that metallocenes can dissolve in supercritical $\mathrm{CO}_{2}$. Reactivity and PCET reactions at this biphasic system will be reported in the near future.

\section{References}

1 J. Clavilier, R. Faure, G. Guinet and R. Durand, J. Electroanal. Chem., 1980, 107, 205-209.

2 S. Fierro, T. Nagel, H. Baltruschat and C. Comninellis, Electrochem. Commun., 2007, 9, 1969-1974.

3 H. Girault, J. Electroanal. Chem., 2010, 23, 1-104.

4 G. Luo, S. Malkova, J. Yoon, D. Schultz, B. Lin, M. Meron, I. Benjamin, P. Vanysek and M. Schlossman, Science, 2006, 311, 216-218.

5 A. Olaya, M. Mendez, F. Cortes-Salazar and H. Girault, J. Electroanal. Chem., 2010, 644, 60-66.

6 J. A. Campbell and H. Girault, J. Electroanal. Chem., 1989, 266, 465-469.
7 F. Reymond, G. Steyaert, P. Carrupt, B. Testa and H. Girault, J. Am. Chem. Soc., 1996, 118, 11951-11957.

8 V. Gobry, S. Ulmeanu, F. Reymond, G. Bouchard, P. Carrupt, B. Testa and H. Girault, J. Am. Chem. Soc., 2001, 123, 10684-10690.

9 H. Hotta, S. Ichikawa, T. Sugihara and T. Osakai, J. Phys. Chem. $B, 2003,107,9717-9725$.

10 H. Tatsumi and H. Katano, Anal. Sci., 2004, 20, 1613-1615.

11 B. Su, I. Hatay, F. Li, R. Partovi-Nia, M. A. Mendez, Z. Samec, M. Ersoz and H. H. Girault, J. Electroanal. Chem., 2010, 639, $102-108$

12 A. Stewart, J. Campbell, H. Girault and M. Eddowes, Ber. Bunsen-Ges. Phys. Chem., 1990, 94, 83-87.

13 I. Hatay, B. Su, F. Li, M. A. Mendez, T. Khoury, C. P. Gros, J.-M. Barbe, M. Ersoz, Z. Samec and H. H. Girault, J. Am. Chem. Soc., 2009, 131, 13453-13459.

14 H. Ohde, K. Maeda, Y. Yoshida and S. Kihara, Electrochim. Acta, 1998, 44, 23-28.

15 M. Suzuki, M. Matsui and S. Kihara, J. Electroanal. Chem., 1997, 438, $147-151$.

16 T. Okugaki, M. Kasuno, K. Maeda and S. Kihara, J. Electroanal. Chem., 2010, 639, 67-76.

17 U. Muellerwesterhoff and A. Nazzal, J. Am. Chem. Soc., 1984, 106, $5381-5382$.

18 A. Karlsson, G. Hilmersson and P. Ahlberg, J. Phys. Org. Chem., 1997, 10, 590-592.

19 U. Koelle, P. Infelta and M. Gratzel, Inorg. Chem., 1988, 27, 879-883.

20 I. Hatay, B. Su, F. Li, R. Partovi-Nia, H. Vrubel, X. Hu, M. Ersoz and H. H. Girault, Angew. Chem., Int. Ed., 2009, 48, $5139-5142$.

21 T. Bitterwolf and A. Ling, J. Organomet. Chem., 1972, 40, 197-203.

22 M. McKee, J. Am. Chem. Soc., 1993, 115, 2818-2824.

23 T. Curphey, J. Santer, M. Rosenblum and J. Richards, J. Am. Chem. Soc., 1960, 82, 5249-5250.

24 B. Su, I. Hatay, P. Y. Ge, M. Mendez, C. Corminboeuf, Z. Samec, M. Ersoz and H. H. Girault, Chem. Commun., 2010, 46, $2918-2919$.

25 V. Cunnane, G. Geblewicz and D. Schiffrin, Electrochim. Acta, 1995, 40, 3005-3014.

26 H. Ohde, K. Maeda, Y. Yoshida and S. Kihara, J. Electroanal. Chem., 2000, 483, 108-116.

27 P. Liljeroth, B. Quinn and K. Kontturi, Langmuir, 2003, 19, 5121-5127.

28 B. Su, R. P. Nia, F. Li, M. Hojeij, M. Prudent, C. Corminboeuf, Z. Samec and H. H. Girault, Angew. Chem., Int. Ed., 2008, 47, 4675-4678.

29 F. Li, B. Su, F. C. Salazar, R. P. Nia and H. H. Girault, Electrochem. Commun., 2009, 11, 473-476.

30 J. Collman, M. Marrocco, P. Denisevich, C. Koval and F. Anson, J. Electroanal. Chem., 1979, 101, 117-122.

31 H. Imahori and S. Fukuzumi, Adv. Funct. Mater., 2004, 14, 525-536.

32 C. Shi and F. Anson, Anal. Chem., 1998, 70, 3114-3118.

33 C. Shi and F. Anson, J. Phys. Chem. B, 1998, 102, 9850-9854.

34 C. Shi and F. Anson, J. Phys. Chem. B, 1999, 103, $6283-6289$.

35 T. Chung and F. Anson, Anal. Chem., 2001, 73, 337-342.

36 T. Chung and F. Anson, J. Electroanal. Chem., 2001, 508, 115-122.

37 R. Partovi-Nia, B. Su, F. Li, C. P. Gros, J.-M. Barbe, Z. Samec and H. H. Girault, Chem.-Eur. J., 2009, 15, 2335-2340.

38 R. Partovi-Nia, B. Su, M. Mendez, B. Habermeyer, C. Gros, J.-M. Barbe, Z. Samec and H. Girault, ChemPhysChem, 2010, 11, 2979-2984.

39 B. Su, I. Hatay, A. Trojanek, Z. Samec, T. Khoury, C. P. Gros, J.-M. Barbe, A. Daina, P.-A. Carrupt and H. H. Girault, J. Am. Chem. Soc., 2010, 132, 2655-2662.

40 B. Su, F. Li, R. Partovi-Nia, C. Gros, J.-M. Barbe, Z. Samec and H. H. Girault, Chem. Commun., 2008, 5037-5038.

41 A. Trojanek, J. Langmaier, B. Su, H. H. Girault and Z. Samec, Electrochem. Commun., 2009, 11, 1940-1943.

42 N. Eugster, D. Fermin and H. Girault, J. Phys. Chem. B, 2002, 106, 3428-3433. 
43 N. Eugster, D. Fermin and H. Girault, J. Am. Chem. Soc., 2003, 125, 4862-4869.

44 N. Eugster, H. Jensen, D. Fermin and H. Girault, J. Electroanal. Chem., 2003, 560, 143-149.

45 C. Shi, B. Steiger, M. Yuasa and F. Anson, Inorg. Chem., 1997, 36, 4294-4295.
46 A. Krieger-Liszkay, C. Fufezan and A. Trebst, Photosynth. Res., 2008, 98, 551-564.

47 Z. Samec, J. Langmaier and T. Kakiuchi, Pure Appl. Chem., 2009, 81, 1473-1488.

48 A. Volkov, M. Gugeshashvili, A. Mironov and L. Boguslavsky, Bioelectrochem. Bioenerg., 1982, 9, 551-558. 